\title{
Survey on Usage of Weekly Hydroxychloroquine Prophylaxis against COVID19 amongst Healthcare Workers in India
}

\author{
Satya Yadav ${ }^{1}$, Intezar Mehdi ${ }^{2}$, Goutomi Chatterjee ${ }^{1}$, Atanu Chatterjee ${ }^{3}$, Rachna \\ Keshwani $^{4}$, Poulomi Chatterjee ${ }^{5}$, Satyendra Katewa ${ }^{5}$, Neha Rastogi ${ }^{1}$, Srikanth Marda ${ }^{6}$, \\ Gaurav Kharya ${ }^{7}$, and Sirisha Rani Siddaiahgari ${ }^{6}$ \\ ${ }^{1}$ The Medicity Hospital \\ ${ }^{2} \mathrm{HCG}$ Hospital \\ ${ }^{3}$ Vivekananda Institute of Medical Sciences \\ ${ }^{4}$ Mewati Government Medical College and Hospital, Lokmanya Tilak Municipal Medical \\ College \& Hospital \\ ${ }^{5}$ Affiliation not available \\ ${ }^{6}$ Rainbow Children's Hospital \\ ${ }^{7}$ Pediatric Hematology Oncology \& BMT Unit, Cancer Institute, Medanta -The Medicity, \\ Indraprastha Apollo Hospital
}

October 14, 2020

\section{To the editor:}

Covid19 pandemic started in Dec 2019 and has affected >10 million people (1). Despite usage of personal protective equipment many healthcare workers (HCW) have been affected globally with Covid19 and some have died (2-4). We need a chemoprophylaxis drug which can stop viral replication and hydroxychloroquine (HCQ) has been shown to do that in-vitro (5). There have been few studies on usage of HCQ for treatment of covid19 with mixed results (6-7). HCQ for post-exposure prophylaxis (a 5-day course) in a randomised control trial showed no benefit (8). Indian council of medical research (ICMR) had recommended weekly prophylaxis (400 mg once a week) for all $\mathrm{HCW}$ in contact or looking after proven Covid19 cases (9). As per a recent report from India 4 or more weekly HCQ doses give better protection against Covid19 in HCW (10). However, questions have been raised about safety \& efficacy of HCQ as a prophylaxis for Covid19. We did a survey across 11 hospitals in 7 cities in India about HCQ prophylaxis amongst HCW.

A total of $301 \mathrm{HCW}$ reported to be taking HCQ $400 \mathrm{mg}$ once a week dose. Hospitals were located in big cities (Mumbai, Delhi, Kolkata, Hyderabad, Gurgaon, Jaipur, Bangalore) designated as Covid19 hotspots. Males were 186 and females were 115. Median age was 34 years (range 22-65 years). Doctors were 126, nurses were 169 and others were 6 . All were working in hospitals treating Covid19 patients. Only $3 \mathrm{HCW}$ stopped HCQ (1 due to headache and other 2 got bored). Median weekly doses taken were 9 (range 1-10). Nearly 50\% (151/301) had taken HCQ weekly for 9 weeks. Side effects were seen in 17 people (nausea-7, gastritis-5, joint pain-1, sweating-1, constipation-1, vertigo-1 \& headchae-1). ECG was not done and G6PD assay was also not done for anyone. From drug interaction point of view, $11 \mathrm{HCW}$ were on additional drugs. Amlodipine and losartan were being taken by 5 people each, 3 were on metformin, 1 on insulin and 2 were on other drugs. Four (1.3\%) developed Covid19 within 2 weeks of starting HCQ and all had mild disease (fever and mild cough) and recovered fully. None needed oxygen or intensive care.

A total of $108 \mathrm{HCW}$ were not taking HCQ working in the same hospitals. Median age was 32.5 years (range 
23-64 years). Male to female ratio was 1:2. Doctors were 35, Nurses-66 and others-7. Amongst them 29 (27\%) developed Covid19. All had mild symptoms but 2 needed oxygen and ICU stay. All recovered fully. So only $1.3 \%$ developed covid19 amongst HCW on HCQ prophylaxis vs. $27 \%$ in those not taking HCQ prophylaxis ( $\mathrm{p}$ value $<0.0001$ ).

In conclusion, its feasible to give safely weekly HCQ prophylaxis to HCW. It seems to effective but a survey is not the best scientific approach to prove efficacy. A randomised controlled trial is needed to confirm efficacy of weekly HCQ amongst HCW.

Disclosure - All authors have nothing to declare.

Contribution - All authors have contributed to this manuscript.

\section{Funding - Nil}

\section{References}

1. Coronavirus Outbreak. Available at: https://www.worldometers.info/coronavirus/. Accessed 28 June, 2020.

2. Characteristics of Health Care Personnel with COVID-19 - United States, February 12-April 9, 2020. MMWR Morb Mortal Wkly Rep 2020; 69:477-481. DOI: http://dx.doi.org/10.15585/mmwr.mm6915e6

3. Kluytmans-van den Bergh MFQ, Buiting AGM, Pas SD, et al. Prevalence and Clinical Presentation of Health Care Workers with Symptoms of Coronavirus Disease 2019 in 2 Dutch Hospitals During an Early Phase of the Pandemic. JAMA Netw Open. 2020;3(5): e209673. doi:10.1001/jamanetworkopen.2020.9673

4. The Lancet. COVID-19: protecting health-care workers. Lancet . 2020;395(10228):922. doi:10.1016/S0140-6736(20)30644-9

5. Liu, J., Cao, R., Xu, M. et al. Hydroxychloroquine, a less toxic derivative of chloroquine, is effective in inhibiting SARS-CoV-2 infection in vitro. Cell Discov 6, 16 (2020). https://doi.org/10.1038/s41421020-0156-0

6. Million M, Lagier JC, Gautret P, Colson P, Fourier P-E, Amrane S, et al. Early treatment of COVID-19 patients with hydroxychloroquine and azithromycin: A retrospective analysis of 1061 cases in Marseille, France. Travel Med Infect Dis. 2020 May 5; 101738

7. RECOVERY trial statement. Statement from the Chief Investigators of the Randomised Evaluation of COVid-19 thERapY (RECOVERY) Trial on hydroxychloroquine. (5 June 2020). https://www.recoverytrial.net/files/hcq-recovery-statement-050620-final-002.pdf

8. Boulware DR, Pullen MF, Bangdiwala AS, et al. A randomized trial of hydroxychloroquine as postexposure prophylaxis for Covid-19. N Engl J Med. DOI: 10.1056/NEJMoa2016638.

9. Indian Council of Medical Research. Advisory on the use of hydroxy-chloroquine as prophylaxis for SARS-CoV-2 infection. New Delhi: ICMR; 2020 Mar 21[cited 2020 May 06]. Available from: https://www.mohfw.gov.in/pdf/ Advisory on the use of hydroxychloroquine as prophylaxis for SARS COVID19 infection.pdf

10. Chatterjee P, Anand T, Singh KJ, Rasaily R, Singh R, Das S, Singh H, Praharaj I, Gangakhedkar RR, Bhargava B, Panda S. Healthcare workers \& SARS-CoV-2 infection in India: A case-control investigation in the time of COVID-19. Indian J Med Res 2020; 151:459-67 